\title{
RANCANGAN SISTEM PENDUKUNG KEPUTUSAN UNTUK PENERIMAAN PESANAN PADA PERUSAHAAN MAKE TO ORDER DENGAN MODEL MATEMATIKA OPTIMASI
}

\author{
Indro Prakoso $^{1 *}$, Kholida Hanim ${ }^{2}$ \\ ${ }^{1}$ Jurusan Teknik Industri, Fakultas Teknik, Universitas Jenderal Soedirman \\ Jl. Profesor Dr HR Boenyamin, No.708, Dukuhbandong, Grendeng, Purwokerto \\ ${ }^{2}$ Magister Teknik Industri, Fakultas Teknologi Industri, Universitas Islam Indonesia. Yogyakarta \\ Jl. Kaliurang, Km 14,5, Besi, Umbulmartani, Ngemplak, Sleman, Yogyakarta. \\ *e-mail: prakosoindro@unsoed.ac.id
}

\begin{abstract}
Manufacturing companies engaged in the system of making orders are now starting to develop with increasingly diverse needs, and the business of making agricultural and food processing machinery is no exception. UD. rekayasa Wangdi $\mathrm{W}$ produced the machine processing manufacturing companies engaged in the make to order system are now starting to develop rapidly along with increasingly diverse needs, and the business of making agricultural and food product processing machines is no exception. UD. Wangdi W Engineering is a Make To Order (MTO) manufacturer of processing machines which currently does not consider resource capacity and order due to date as a reference for receiving orders. Even though accepting all orders does not necessarily provide maximum benefits. To help solve these problems, a decision support system design for planning the acceptance of customer orders is carried out. The system is designed using a mathematical model that was developed and modified in linear programming. The model developed has an objective function of maximizing profits from orders received and applied in the system built. The system is designed and the Mathematical Model is processed using the branch and bound method. Based on experimentation with historical data, the results obtained are only 4 slicer and 10 spinner units with a maximum profit of Rp. 53,115,530.00 and order completion that does not exceed the due date. Order acceptance information is displayed in tabular form and machine scheduling information is displayed in Gantt chart format.
\end{abstract}

Keywords: Decision Support System, Make to Order and Math Optimization.

\section{Pendahuluan}

Proses produksi dalam perusahaan merupakan hal penting dan perlu perbaikan terus menerus, dimulai sejak pengelolaan permintaan, estimasi biaya, master production planning, perencanaan material, capacity management, dan order release. Keinginan pasar yang semakin inovatif memaksa perusahaan melakukan perubahan agar mampu bersaing dengan tingginya persaingan pasar saat ini (Parkham et al. 2005). Kesuksesan suatu perusahaan diukur dari tingkat kemampuan perusahaan menyesuaikan diri dengan berubahubahnya permintaan pelanggan dan mampu melakukan produksi dengan biaya yang minimal (Żywicki et al. 2019). Proses manufaktur make to order memiliki masalah yang mendasar, yaitu membuat banyak macam permintaan (Żywicki et al. 2019).

UD Rekayasa Wangdi W merupakan model perusahaan make to order yang bergerak dalam bidang pembuatan mesin-mesin bantu dalam bidang makanan, pengolah hasil pertanian, dan hasil peternakan. Perusahaan ini yang mampu memenuhi permintaan konsumen dengan spesifikasi yang sudah standar dan produk yang memiliki spesifikasi yang khusus diinginkan oleh konsumen sendiri. Ketika konsumen melakukan permintaan dengan spesifikasi produk yang khusus sesuai dengan permintaan konsumen, permintaan seperti ini sangat menyulitkan pemangku kebijakan dalam menentukan biaya produksi, sistem produksi, penjadwalan dan lain sebagainya. Sedangkan konsumen ingin mendapatkan jawaban untuk kualitas produk, harga produk dan kapan produk itu selesai dibuat dalam waktu yang cepat atau bahkan diawal waktu konsumen melakukan pemesanan. Di satu sisi perusahaan ini masih bersifat tradisional dan dalam menentukan keputusan memerlukan waktu yang lama dan belum memiliki sistem tersendiri. Maka dari itu pemangku kebijakan membutuhkan cara cepat untuk menjawab masalah dari konsumen tersebut. Model jaringan yang 
memonitor antrian pesanan dalam kegiatan make to order perlu diperhatikan secara khusus untuk memberikan kualitas produk dan layanan yang baik, tidak terkecuali memperhatikan penjadwalan produksi (Yao.X et al.. 2017).

Sistem pendukung keputusan saat ini sangat diperlukan untuk membantu para petani dan pelestarian lingkungan tidak terkecuali perusahaan pembuat mesin pengolah pertanian (Fink. C. 2018). Dalam sistem pendukung keputusan untuk penerimaan pesanan pelanggan dalam penelitian ini menggunakan pemodelan matematika untuk menyelesaikan masalah penerimaan pesanan berdasarkan kapasitas dan dengan keuntungan yang optimal. Model matematika ini merupakan model yang dibuat oleh Chen et al (2009) dan dikembangkan dan disesuaikan dengan masalah make to order pada UD Rekayasa Wangdi. Model ini merupakan perencanaan kapasitas untuk pemilihan pesanan yang diterima serta penjadwalan pesanan agar tidak melebihi due date untuk perusahaan make to order.

\section{Landasan Teori}

\subsection{Lingkungan Make To Order}

Pada lingkungan make to order (MTO) biasanya memiliki konfigurasi jenis produk yang besar dan permintaan konsumen untuk setiap spesikfikasi produk atau karakteristik produk yang akan diproduksi sulit untuk diperkirakan. (Parkam et al. 2005). Proses penjadwalan yang biasanya digunakan dalam perusahaan manufaktur yang menggunakan sistem MTO adalah berdasarkan process layout atau job shop scheduling. Dikarenakan beragamnya konfigurasi produk namun bergantung dengan jumlah bahan baku yang tersedia dan biasanya produk yang dibuat berasal dari bahan baku yang sama atau mirip untuk memudahkan dalam pengerjaanya maka terjadi besarnya perbedaan proses pengerjaan atau produksi dalam sistem manufaktur.

\subsection{Sistem Pendukung Keputusan}

Sistem adalah sekumpulan dari objek-objek seperti orang, resource, konsep dan prosedur yang ditunjukan untuk melakukan fungsi tertentu atau memenuhi suatu tujuan. Koneksi antara dan inetraksi sub sistem disebut dengan antar muka / interface. sistem terdiri dari : input, proses dan output. (Subakti, 2002). Menurut Subakti (2002) hal yang mempengaruhi sistem tidak hanya input, proses dan output, dalam sistem juga terdapat feedback, yaitu aliran informasi dari komponen output ke pengambilan keputusan yang memperhitungkan output atau kinerja sistem. Dari informasi ini, pengambil keputusan yang bertindak sebagai pengontrol bisa memutuskan untuk memodifikasi input, proses atau keduanya.

\subsection{Model Perencanaan Kapasitas}

Adapun model yang digunakan sebagai referensi untuk masalah penerimaan pesanan adalah model perencanaan kapasitas yang dibuat dan dikembangkan oleh Chen et al (2009). Model ini merupakan model yang dibuat untuk membantu dalam pengambilan keputusan penerimaan pesanan dengan mempertimbangkan kapasitas yang tersedia agar perusahaan dapat memperoleh profit yang maksimal serta tingkat keterlambatan yang minimal. Pada model ini juga mengusulkan perencanaan kapasitas produksi tiap pesanan dengan mempertimbangkan kapasitas waktu regular, overtime, dan outsourcing

\section{Metodologi Penelitian}

Penelitian ini adalah pada UD Rekayasa Wangdi W, Dusun Cambahan, Nogotirto, Gamping, Sleman, Yogyakarta. Perusahaan ini memproduksi mesin-mesin pengolah, seperti mesin bantu pengolah hasil pertanian, dan pengolah hasil peternakan. Data yang diambil adalah berupa: Jumlah Produksi (unit), Desain dan Ukuran dimensi dari beberapa jenis produk mesin bantu (cm), Bahan baku, Penjadwalan (jam), Bill of Materrial, Proses Produksi, Persediaan Material, Waktu siklus produk (jam), Permintaan produk (unit), Harga jual produk, Lead time (jam), Biaya Produksi. Metode analisis yang digunakan dalam penelitian ini adalah verifikasi dan validasi sistem yang telah dibuat. Verifikasi dilakukan untuk menguji apakah sistem yang telah dibuat dapat berjalan dengan baik tanpa terjadi kesalahan (error) dan perhitungan pada sistem sesuai dengan perhitungan manual atau tidak. Sedangkan validasi dilakukan untuk mengetahui apakah sistem yang telah dibuat sesuai dengan sistem nyata yang berjalan pada perusahaan atau tidak. Data yang diambil untuk eksperimentasi uji sistem dikhususkan untuk 3 produk yang sering dipesan, yaitu mesin mixer, slicer dan spiner, data adalah kebutuhan bahan baku 3 produk tersebut. Selain data bahan baku, data proses permesinan dan biaya tenaga kerja juga dibutuhkan, untuk ketiga produk tersebut. Kemudian data waktu pengerjaan produk juga dibutuhkan, dan harga bahan baku juga menjadi pertimbangan dalam perhitungan model. Biaya tenaga kerja, kapasitas waktu produksi dan kapasitas waktu kerja juga menjadi pertimbangan dalam penyelasian masalah. 


\subsection{Pengembangan Model}

Untuk menyelesaikan masalah yang terdapat dalam penelitian ini maka dibangunlah sebuah model matematika. Model yang dibangun terdapat beberapa pengembangan yaitu pada jumlah indeks dan pembagian waktu kerja. Dalam membangun suatu model matematika digunakan beberapa asumsi yaitu: 1. Model matematika yang dikembangkan adalah untuk keadaan dimana terdapat beberapa konsumen yang datang ke perusahaan untuk memesan produk. 2. Data down time kerusakan mesin-mesin di perusahaan diabaikan. 3. Jam kerja yang terdapat di perusahaan adalah jam kerja reguler yaitu jam 08.00-16.00 dan jam kerja le mbur yaitu jam 16.00-21.00. Namun untuk jam kerja lembur di UD. Rekayasa Wangdi W jarang digunakan, oleh karena itu pada model matematika yang dikembangkan tidak menggunakan jam kerja lembur. 4. Permintaan due date dari konsumen akan menjadi pertimbangan bagi perusahaan dalam mengerjakan produk, namun due date dari konsumen ini bukanlah due date yang sebenarnya dalam artian masih ada toleransi untuk due date yang diminta dari konsumen.

Maksimasi

$\sum_{i \in I} s_{i} Z_{i}-\sum_{i \in I} \sum_{j \in J} \sum_{k \in K} \sum_{t \in T} c_{k} X_{i j k t}$

Batasan

$$
\begin{aligned}
& \sum_{i \in I} \sum_{j \in J} \sum_{k \in K} Y_{i j k t} \leq 1 ; \forall i \in I, j \in J, k \in K, t \in T \\
& \sum_{i \in I} \sum_{j \in J} X_{i j k t} \leq b_{k t} ; \forall k \in K, t \in T \\
& \sum_{k \in K} \sum_{t \in T} X_{i j k t}=p_{i j k} Z_{i} ; i \forall I, j \forall J, k \forall K
\end{aligned}
$$

$\sum_{j \in J} \sum_{k \in K} X_{i j k t} \leq 8 ; \forall i \in I, j \in J, k \in K, t \in T$

$X_{i j k t} \geq Y_{i j k t} ; \forall i \in I, j \in J, k \in K, t \in T$

$X_{i j k t} \leq p_{i j k} Y_{i j k t} ; \forall i \in I, j \in J, k \in K, t \in T$

$\sum_{k \in K} t Y_{i|j| k t} \leq d_{i} Z_{i} ; \forall i \in I, j \in J, k \in K, t \in T$

$\sum_{k \in \mathbb{R} t=1}^{t-1} \sum_{i(j-1) k t}+\sum_{k \in \mathbb{R}} X_{i(j-1) k t} \geq \sum_{k \in \mathbb{R}} p_{i(j-1) k} Y_{i j k t} ; \forall i \in l, j \in J, t \in T$

$X_{i j k t} \geq 0 ; \forall i \in I, j \in J, k \in K, t \in T$

$Y_{i j k t}$ Binary; $\forall i \in I, j \in J, k \in K, t \in T$

\section{$Z_{i}$ Binary; $\forall i \in I$}

Fungsi tujuan atau persamaan (1) adalah maksimasi keuntungan yang diperoleh dari harga jual dikalikan dengan jumlah produk yang diproduksi dikurangi dengan biaya sumberdaya yang digunakan untuk memproduksi produk tersebut. Persamaan (2) merupakan batasan yang menjamin bahwa satu sumberdaya hanya dapat mengerjakan satu operasi untuk satu pesanan dalam tiap periode. Persamaan (3) merupakan batasan kapasitas waktu sumberdaya tiap periode, dimana waktu produksi yang digunakan untuk setiap operasi produk pada tiap sumberdaya tidak boleh lebih dari kapasitas waktu yang dimiliki sumberdaya $\mathrm{k}$ pada periode t. Persamaan (4) memastikan bahwa jumlah waktu operasi $j$ untuk pesanan i pada sumberdaya $k$ di periode waktu $t$ harus sama dengan waktu proses penyelesaian pesanan i pada operasi $\mathrm{j}$ oleh sumberdaya $\mathrm{k}$. Persamaan (5) menunjukkan bahwa kapasitas waktu untuk setiap periode adalah 8 jam. Persamaan (6) dan (7) mengharuskan nilai variabel keputusan $Y_{i j h t}$ bernilai 0 atau 1 . Sehingga lama waktu operasi $\mathrm{j}$ untuk pesanan $\mathrm{i}$ pada sumberdaya $\mathrm{k}$ di periode waktu $\mathrm{t}$ tidak melebihi waktu proses penyelesaian pesanan i pada operasi j oleh sumberdaya k. Persamaan (8) memastikan bahwa ketika suatu pesanan diterima, maka waktu penyelesaian operasi terakhir untuk pesanan tersebut tidak melebihi due date yang telah ditentukan. Persamaan (9) memastikan bahwa operasi $\mathrm{j}$ untuk pesanan $\mathrm{i}$ dapat diproses pada periode $t$ setelah operasi $j-1$ selesai dikerjakan. Persamaan (10) memastikan bahwa nilai variabel keputusan $X_{i j h t}$ tidak bernilai negatif, karena variabel $X_{i j h t}$ merupakan waktu operasi pesanan pada setiap periode. Persamaan (11) dan (12) memastikan variabel $Y_{i j h t}$ dan $Z_{i}$ mempunyai nilai biner. Tabel indeks keterangan dari persamaan diatas terdapat pada tabel 1.2 dan 3.

\section{Hasil dan Pembahasan}

\subsection{Rancangan Sistem}

Proses produksi untuk produk standar membutuhkan waktu sekitar 5 hari -7 hari waktu kerja atau sekitar 32,5 jam - 45,5 jam, dikarenakan waktu kerja dalam satu hari 8 jam dan dipotong istirahat dan makan selama 1,5 jam. Proses produksi untuk beberapa produk standar, dengan waktu satndar dan material yang standar seperti produk Mixer, Spiner, Slicer dan semua produk secara umum dapat digambarkan sebagai berikut : 


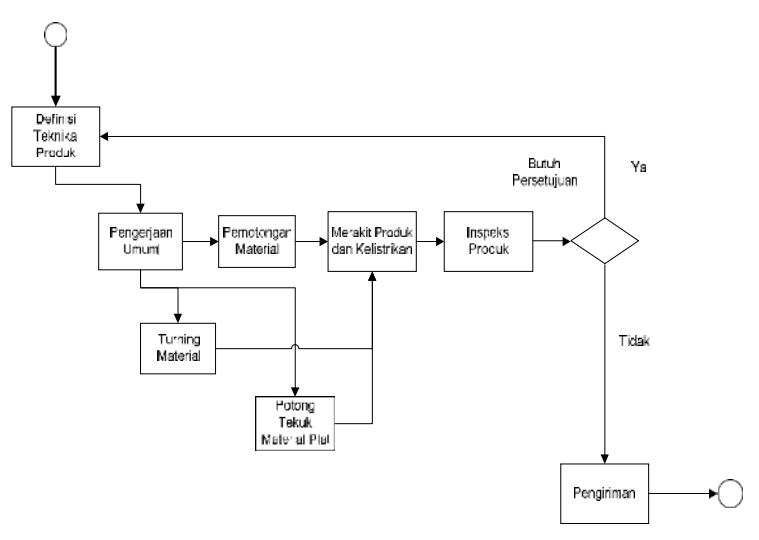

Gambar 1. Proses Produksi Secara Umum Sumber : Pengolahan Data

Konsep kerangka kerja sistem pendukung keputusan yang dibuat menggunakan prinsip dasar kerangka kerja untuk sistem pendukung keputusan dengan berbasis simulasi, karena sangat cocok dengan model produksi make to order (Żywicki K et al. 2019). Namun disini model yang digunakan tidak berbasis pada simulasi namun diganti dengan uji eksperimentasi dan menggunakan model matematika dari data manufaktur yang didapat secara manual. Ketika konsumen datang dan memesan produk baik dengan desain sendiri, modifikasi maupun standar, manajer mampu ataupun paling tidak memberikan gambaran kapan produk selesai dan besaran harga yang harus dibayar konsumen saat itu juga tanpa menunda sampai 3-4 hari terutama untuk produk dengan desain tersendiri dan produk modifikasi. Kerangka kerja sistem bertujuan untuk menggambarkan rancangan sistem yang akan dibuat sesuai dengan alur proses pada perusahaan. Pada kerangka kerja ditunjukan komponen apa saja yang menjadi dasar rancangan sistem. Komponen ini disesuaikan dengan keadaan yang sebenarnya pada perusahaan, sehingga pada kasus yang berbeda memiliki kerangka kerja sistem yang berbeda. Selain kerangka kerja sistem yang digunakan sebagai awalan atau planning kemudian dibuat diagram konteks yang menunjukan aliran data secara umum pada sistem yang akan dibangun, dan membuat tabel kejadian dan respon dengan tujuan untuk mengetahui aliran proses. Tahapan selanjutnya adalah merancang diagram aliran data atau bisa disebut juga dengan diagram sistem, merupakan penyatuan atau gabungan dari keseluruhan diagram kejadian (event diagram), pada tahap ini semua entitas disatukan.

Ketika pelanggan atau pemesan datang secara satu persatu, pengguna tidak perlu menggunakan subsistem model matematika untuk mendapatkan informasi pendukung keputusan penerimaan pesanan, pengguna hanya mendapatkan informasi dari sistem ini berupa tabel jadwal produksi dari pesanan yang telah diterima sebelumnya. Dari informasi ini pengguna dapat memanfaatkan kepakaranya dengan bantuan pendukung keputusan berupa data jadwal produksi pemesanan yang sudah diterima untuk menerima pesanan. Jadwal produksi tersebut berdasarkan pada jadwal produksi dari masing-masing pekerja, dikarenakan jadwal pekerja sangat mempengaruhi kapan produk yang dipesan itu diproduksi dan kapan produk yang dipesan tersebut selesai diproduksi. Informasi ini sangat penting untuk memastikan kepada pelanggan bahwa produk yang dipesan akan selesai pada waktu tertentu sehingga pelanggan akan mengerti lanon nrodul itu calacoi dilariolan

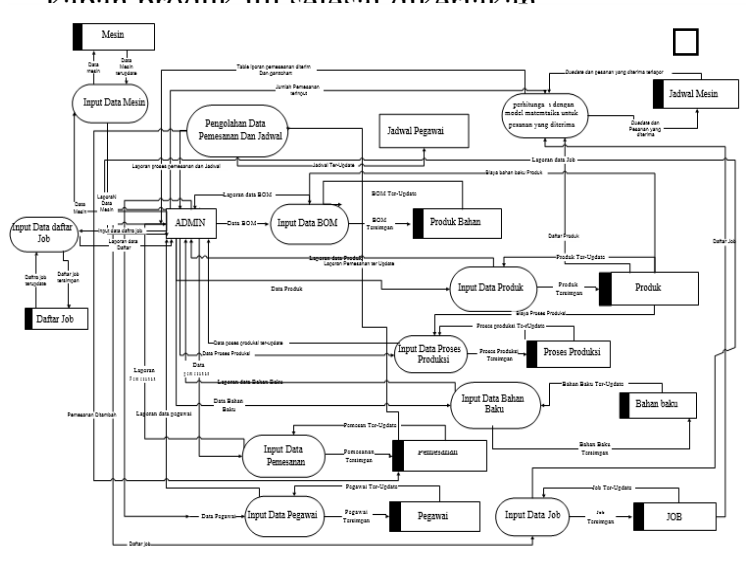

Gambar 2. Diagram Aliran data Sumber : Pengolahan Data

Semua aliran data ditunjukan pada gambar 2, dengan semua komponen data yang dibutuhkan disatukan dari data base masing-masing. Dalam suatu sistem bisnis, secara grafis untuk menandai proses dan aliran data ditunjukan secara detail dalam diagram alir data dan menggambarkan desain system yang di bangun (Afyenni. 2014).

\subsection{Penerapan Model Matematika}

Model matematika optimasi dengan kompleksitasnya dapat digunakan dalam berbagai kasus dan berbagai penerapan (Jamaluddin et al. 2011). Perhitungan pada sistem pendukung keputusan dengan model penerimaan pesanan menggunakan software lingo 8.0, ini dikarenakan panjangnya iterasi dalam hitungan sehingga tidak memungkinkanya melakukan perhitungan manual pada software Visual Basic 6.0. Untuk perhitungan model biaya produk pada sistem pendukung keputusan yang dirancang tidak menggunakan software tambahan seperti pada model penerimaan pesanan. Pada model ini perhitungan dilakukan langsung pada software visual basic 6.0. Berikut ini flowchart proses perhitungan model biaya produksi ditunjukan pada gambar 3 . 


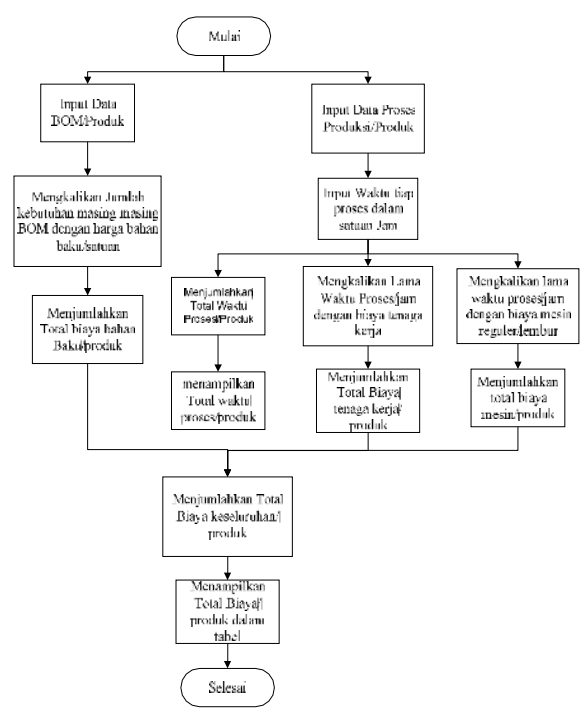

Gambar 3. Flowchart Perhitungan Biaya Produk Sumber : Pengolahan Data

\subsection{Perancangan Usher Interface}

Sistem user interface pesanan ini sangat penting untuk dirancang sesuai dengan kebutuhan sistem dan kesesuaian kegunaan admin dalam pengoprasianya (Dudley.J.J \& Per Ola. 2018) Perancangan interface juga disesuaikan dengan tampilan yang sederhana dan dapat dengan mudah dimengerti oleh pengguna. Perancangan user interface pada sistem yang dirancang ini terdiri dari 1 menu utama, yaitu halaman HOME. Dari HOME ini pengguna dapat memilih menu INPUT, menu PEGAWAI, menu JOB, menu PENGAMBILAN KEPUTUSAN, menu PEMESANAN dan menu EXIT. Untuk hasil pengambilan keputusan pada sistem ini akan ditampilkan pada halaman hasil pengambilan keputusan. Berikut ini rincian dan penjelasan dari masing-masing menu interface.

Pada halaman pemesanan, digunakan untuk memasukan data pemesanan dari pelanggan. Pada halaman ini pengguna dan pemesan mendapatkan informasi tentang produk yang dipesan, jumlah yang dipesan, due date, harga produk yang dipesan, pegawai yang mengerjakan produk yang dipesan, kapan pekerjaan dimulai dan kapan produk yang dipesan selesai dikerjakan atau diproduksi. Dari data inputan ini akan mengupdate secara otomastis ke tampilan input PEGAWAI yang dijelaskan sebelumnya pada bagaian jadwal, sehingga data pesanan bertambah maka data jadwal pekerja juga bertambah. Dari informasi yang didapat dari halaman ini pengguna juga dapat menentukan keputusan untuk perencanaan penerimaan pesanan. Halaman ini bersifat umum sehingga siapapun dapat mengakses dan melihat halaman ini termasuk pelanggan, ditunjukan pada gambar 4 .

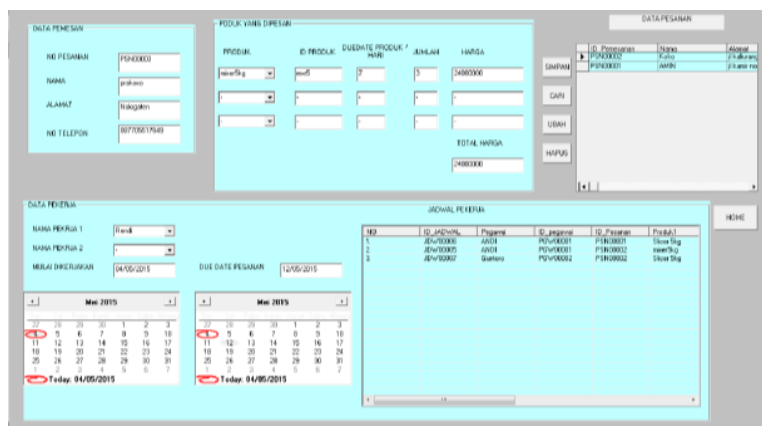

Gambar 4. Desain User Interface Halaman Input Data Pemesanan Sumber : Pengolahan Data

Pada halaman selanjutnya pengguna mendapatkan informasi dari hasil perhitungan model matematika berupa tabel penjadwalan, tabel pemesanan yang diterima, kolom teks keuntungan maksimal dan ganttchart penjadwalan. Data yang digunakan di ambil dari data berupa file txt dari software notepad yang kemudian di tampilakan pada antar muka ini.

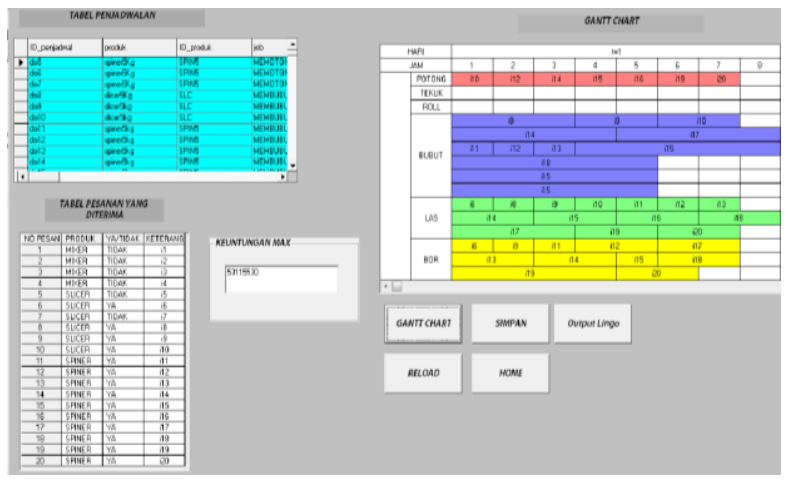

Gambar 5. Desain User Interface Halaman Hasil Penjadwalan dan Optimalisasi Pesanan Sumber : Pengolahan Data

Pada sistem ini pengguna juga tidak hanya disajikan penjadwalan dalam bentuk tabel namun juga dalam bentuk gantt chart untuk mempermudah dalam membaca jadwal produksi berdasarkan sumber daya mesin. Desain user interface pengguna dirancang dengan memperhatikan konsistensi antar muka, mudah di kontrol dan tidak membebankan penyimpanan. (S. Sridevi, 2014)

Menggunakan data historis sebagai ekperimentasi diperoleh hasil bahwa tidak semua pesanan diterima. Untuk output total biaya produk dari model yang digunakan dapat diketahui total biaya produksi untuk produk mixer, slicer dan spiner yaitu Rp 4.134.137,00 , Rp 2.300.329 dan Rp 2.854.716 dan adapun pesanan yang diterima berdasarkan nilai varibel keputusan $Z_{i}$ adalah 4 
unit produk 2 (slicer) dan 10 unit produk 3 (spiner) dengan keuntungan maksimal adalah Rp53.115.530,00. Hasil ini adalah sebagai uji sistem dan keputusan penerimaan pesanan tetap mutlak ditangan pemangku kebijakan, sistem dirancang untuk membantu pengambilan keputusan dan memerluas kabailitas pemangku kebijakan (Ernawati et al. 2017).

\section{Kesimpulan}

Sistem pendukung keputusan yang telah dirancang dapat digunakan untuk menentukan penerimaan pesanan apabila pemesan datang secara bersamaan dan juga dapat digunakan untuk menentukan kapan pesanan dikerjakan, kapan pesanan selesai dikerjakan dan siapa pegawai yang mengerjakan apabila pesanan yang datang tidak secara bersamaan. Pengolahan matematika optimasi untuk pesanan dengan data historis sebagai ekperimentasi didapatkan nilai yang optimal dengan 4 unit produk slicer dan 10 unit produk spiner dengan keuntungan maksimal Rp53.115.530,00. Sistem dapat berjalan dengan baik dengan diimplementasikan pada software Visual Basic 6.0 dan Lingo 8.0. User interface pada sistem menampilkan tidak hanya disajikan penjadwalan dalam bentuk tabel namun juga dalam bentuk gantt chart

\section{Daftar Referensi}

Afyenni. R. (2014). Perancangan Data Flow Diagram Untuk Sistem Informasi Sekolah ( Studi Kasus Pada SMA Pembangunan Laboratorium UNP). Jurnal Teknoif Institut Teknologi Padang. Vol.2, No.1

Chen C.S., Mestry S., Damodaran P., Wang.C. (2009). The Capacity Planning Problem In Make-To-Order Enterprises. International Journal Of Mathematical and Computer Modelling, 50, 1461-1473.

Dudley. J. J. \& Per Ola. K. (2018). A Review of User Interface Design for Interactive Machine Learning. Journal ACM Transactions on Interactive Intelligent Systems (TiiS) - Special Issue on HumanCentered Machine Learning. Vol 8. Issue 2. No 8 .

Ernawati., Nur Aeni. H., \& Elvi Fetrina. (2017). Rancang Bangun Sistem Pendukung Keputusan Kenaikan Jabatan Pegawai Dengan Metode Profile Matching (Studi Kasus: Kementerian Agama Kantor Wilayah DKI Jakarta). Studia Informatika: Jurnal Sistem Informasi, 10(2), 2017, 127134.

Fink. C, Bo Liu, Fletcher.E, Chandra. K, Rich.
W, Balaji. S. (2018). Design, Development and Evaluation of an Open Source Gateway for the SmartFarm Decision Support System. American Society of Agricultural and Biological Engineers.

Jamaluddin. J., Budi Raharjo, Pudji Hastuti, \& R Rochmadi. (2011). Model Matematika Optimasi untuk Perbaikan Proses Penggorengan Vakum Terhadap Tekstur Keripik Buah. Jurnal Teknik Industri. Vol.12, No.1.

Parkham, Ali dan Tanjung, H.A (2005). Minimasi Slack Time Pada Penjadwalan Make To Order Job Shop. Performa. Vol.4, No.2:107-116.

S.Sridevi. (2014). User Interface Design. International Journal of Computer Science and Information Technology Research. Vol. 2, Issue 2, pp: (415-426)

Subakti, Irfan. (2002). Sistem Pendukung Keputusan (Decision Support System). Institut Teknologi Sepuluh Nopember. Surabaya

Yao. X, Jianming. Z, Yongxiang Li, and Cunji. Z. (2018). Towards flexible RFID eventdriven integrated manufacturing for maketo-order production. Journal International Journal of Computer Integrated Manufacturing. Vol: 31, Issue 3. Page 228.

Żywicki K., Osiński F., Wichniarek R. (2019) Methodology of Estimating Manufacturing Task Completion Time for Make-to-Order Production. In: Machado J., Soares F., Veiga G. (eds) Innovation, Engineering and Entrepreneurship. HELIX 2018. Lecture Notes in Electrical Engineering, vol 505. Springer, Cham 